\title{
A Parametric Study on the Process-Induced Deformation of Composite T-Stiffener Structures
}

\author{
Chensong Dong* \\ Department of Mechanical Engineering \\ Curtin University of Technology

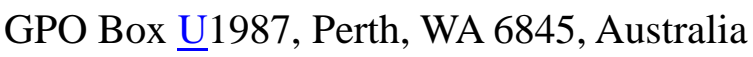

\section{Abstract}

A parametric study on the process-induced deformation of composite stiffener structures is presented in this paper. The deformation was calculated numerically by Finite Element Analysis (FEA). The results suggest that the overall deformation of the structure can be characterized by the spring-in of the skin. Based on FEA, a parametric study and sensitivity analysis was conducted, from which it is shown that: (1) the spring-in decreases with the fiber volume fraction; (2) the spring-in linearly increases with the radius-thickness ratio; (3) the spring-in vs. the bonding length is a power increasing function; (4) the spring-in is most sensitive to the laminate fiber volume fraction, followed by the radius-thickness ratio and the bond length, and least sensitive to the noodle fiber volume fraction; and (5) at higher fiber volume fractions, the spring-in is more sensitive to the fiber volume fraction.

Keywords: A. Polymer-matrix composites (PMCs); B. Residual/internal stress; C. Finite element analysis (FEA)

\footnotetext{
* Tel.: +61 (8) 92669204; fax: +61 (8) 92662681; email: c.dong@curtin.edu.au
} 


\section{Introduction}

Composites offer the advantages of low density, high strength, high stiffness to weight ratio, excellent durability, and design flexibility. Composite T-stiffener structures are widely used in weight sensitive structural, aerospace and marine applications for the purpose of reducing the structure's weight. These integrated structures are often made of flat or curved panels with co-cured or adhesively bonded frames and stiffeners.

T-stiffener composite structures can be made by the prepreg/autoclave or the resin transfer molding (RTM) process. The prepreg/autoclave process can be further categorized into three different processing methods: co-curing, co-bonding and secondary bonding [1]. When the RTM process is used, the whole part is molded as one piece or the spar and skin are molded separately and bonded together with an adhesive [2].

Anisotropy, the main characteristic of composite materials, is an advantage from the perspective of structural design, but is also a main cause of the process-induced deformation. The longitudinal modulus of composites is much higher than the transverse modulus, and the longitudinal CTE is much lower than the transverse coefficient of thermal expansion (CTE) due to the anisotropic nature. After the processing, deformation is induced by the CTE mismatch and curing shrinkage of resin.

Past research on the process-induced deformation of composites was mainly focused on the spring-in of angled parts, i.e. the reduction in the enclosed angle. The spring-in of composites was either studied by elastic or viscoelastic models. When the elastic models were used, both analytical and numerical methods were developed. Hahn and Pagano [3] performed an elastic analysis of the residual stresses in a thermoset matrix composite. Radford and Diefendorf [4] developed a simple mathematical formula to predict the spring-in of curved shaped parts, which was used by Huang and Yang [5] in their experimental studies. Kollar [6] presented an approximate analysis of spring-in. Jain and Mai $[7,8]$ developed a 
mechanics-based model using modified shell theory. It is shown from these studies that the spring-in is independent of the radius or thickness of the composite angled part. However, some other studies [9-11] suggest that the spring-in decreases as the thickness increases. For more complex shapes, numerical methods are often needed. Wang et al. [12] conducted a finite element analysis of spring-in using ABAQUS. Ding et al. [13] developed a 3-D finite element analysis procedure to predict spring-in resulting from anisotropy for both thin and thick angled composite shell structures.

The mechanical behavior of composite materials is better represented by a viscoelastic model. Some studies calculated the residual stress developed during the cooling down stage by thermo-viscoelastic models [14-16]. Others [17-23] also addressed the residual stresses developed before cooldown, i.e. during the curing process. White and Hahn $[17,18]$ studied the residual stress development during the curing of thin laminates by a 2-D finite difference thermo-chemical model and a generalized plane-strain finite element model. Li et al. [19] used a plane-strain, linearly elastic finite element model with temperature-dependent matrix properties to analyze the evolution of residual stresses in graphite-PEEK composites during curing. Wiersma et al. [20] developed a thermo-elastic model and extended it into a thermoviscoelastic model. A plane-strain finite element process model COMPRO was developed to simulate the spring-in and warpage in the autoclave process [21, 22]. Zhu et al. [23] developed a fully 3-D coupled thermo-chemo-viscoelastic finite element model to simulate the heat transfer, curing, and residual stress development during the manufacturing cycle of thermoset composite parts. Despite all these studies on spring-in, the deformation of composite T-stiffener structures has not been studied in depth. Li et al. [24] studied the process-induced deformation of composite T-stiffener structures by finite element analysis. The results show that: (1) both warpage deformation and internal stresses are closely correlated with the fabrication process; and (2) the selection of different fabrication process 
can prominently reduce the warpage deformation and the internal stresses.

From the literature, it can be seen that although the process induced deformation of composites such as spring-in was studied either analytically or numerically, the deformation of T-stiffener structures has not received much attention. A parametric study on the processinduced deformation of composite T-stiffener structures is presented in this paper. The deformation was computed by FEA, and the resulting deformation was characterized by a single angular displacement. For a given material system, the influence of the bond length, the radius, the thickness, and the fiber volume fraction is investigated. The paper is organized as follows: Section 2 presents the modeling and characterization of deformation; Section 3 presents the parametric study; the sensitivity of the deformation to the design parameters are-is studied in Section 4; and finally the conclusions are given in Section 5.

\section{Modeling and Characterization of Deformation}

\subsection{Modeling of material properties}

In order to model the deformation, the material properties of composites including the stiffness and CTE need to be derived. For a composite lamina, its properties are dependent on the constituent properties and fiber volume fraction $V_{f}$. Generally, the properties of fibers are independent of temperature. The CTE and Poisson's ratio of resin is constant below the glass transition temperature $T_{g}$. The elastic modulus of resin, however, is temperaturedependent. As shown in Figure 1, the DMA (Dynamic Mechanical Analysis) results for an epoxy resin suggest that the modulus decreases with the temperature approximately linearly from the room temperature to $T_{g}$. 


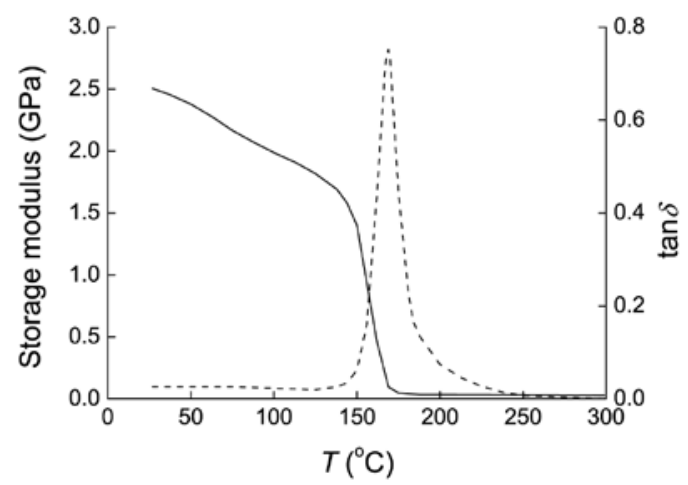

Figure 1: Modulus of epoxy vs. temperature

Another important aspect is that resin will undergo substantial shrinkage. For epoxy resins, this can be $5 \%[25,26]$ or higher [27]. In the beginning of a typical liquid composite molding process, resin is fully uncured and behaves as viscous fluid. During the curing process, resin is heated up to a temperature usually above $T_{g}$. A significant increase in modulus and a reduction in specific volume begin to occur. Approximately 60\% of the total volumetric shrinkage occurs prior to the gel point $[26,27]$. Thus, only a small fraction of curing shrinkage contributes to the residual stress and warpage development. In this study, the volumetric curing shrinkage of epoxy in the glassy state is assumed to be $0.6 \%$.

After the shrinkage is known, it is converted to linear shrinkage by

$$
L_{s} \approx V_{s} / 3
$$

and this linear shrinkage is added to the CTE of epoxy by

$$
\alpha_{m}^{e}=\alpha_{m}+\frac{V_{s}}{3\left(T_{g}-T_{0}\right)}
$$

In this study, the constituent materials are assumed to be AS4 graphite fibers and epoxy resin, and their properties and CTE are shown in Table 1. 
Table 1: Material properties of AS4 graphite fibers and epoxy resin in the glassy state [28]

\begin{tabular}{|c|c|c|c|c|c|c|c|c|}
\hline \multirow[t]{2}{*}{ AS4 graphite fibers } & $\begin{array}{c}E_{f L} \\
(\mathbf{G P a})\end{array}$ & $\begin{array}{c}E_{f T} \\
(\mathbf{G P a})\end{array}$ & $\begin{array}{c}G_{f} \\
(G P a)\end{array}$ & $\begin{array}{c}G_{f T T} \\
(\mathrm{GPa})\end{array}$ & $v_{f}$ & $v_{f T T}$ & $\begin{array}{c}\alpha_{f L} \\
\left(10^{-6} /{ }^{\circ} \mathrm{C}\right)\end{array}$ & $\begin{array}{c}\alpha_{f T} \\
\left(10^{-6} /{ }^{\circ} \mathrm{C}\right)\end{array}$ \\
\hline & 235 & 14 & 6.917 & 5 & 0.2 & 0.4 & -0.4 & 18 \\
\hline \multirow[t]{2}{*}{ Epoxy } & \multicolumn{2}{|c|}{$\begin{array}{c}E_{m} \text { at } 20^{\circ} \mathrm{C} \\
\text { (GPa) }\end{array}$} & \multicolumn{2}{|c|}{$\begin{array}{c}E_{m} \text { at } 150^{\circ} \mathrm{C} \\
\text { (GPa) }\end{array}$} & \multicolumn{2}{|c|}{$v_{m}$} & \multicolumn{2}{|c|}{$\alpha_{m}\left(10^{-6} /{ }^{\circ} \mathrm{C}\right)$} \\
\hline & \multicolumn{2}{|c|}{2.581} & \multicolumn{2}{|c|}{1.620} & \multicolumn{2}{|c|}{0.265} & \multicolumn{2}{|c|}{64} \\
\hline
\end{tabular}

Based on these constituent properties, the lamina properties, including the longitudinal modulus $E_{11}$, the transverse moduli $E_{22}$ and $E_{33}$, and the shear moduli $G_{12}, G_{13}$ and $G_{23}$, are derived by Hashin's model [29] for both the room temperature $\left(20^{\circ} \mathrm{C}\right)$ and $T_{g}\left(150^{\circ} \mathrm{C}\right)$. The stiffness matrix for a lamina $\overline{\mathbf{C}}$ is derived from these lamina properties, and the $\bar{C}_{i j}$ at any temperature $T$ is given by

$$
\bar{C}_{i j, T}=\frac{\bar{C}_{i j, 20}(150-T)+\bar{C}_{i j, 150}(T-20)}{130}
$$

The longitudinal CTE of the lamina is calculated by

$$
\alpha_{11}=\frac{\alpha_{f L} E_{f L} V_{f}+\alpha_{m} E_{m}\left(1-V_{f}\right)}{E_{f L} V_{f}+E_{m}\left(1-V_{f}\right)}
$$

where $\alpha_{f L}$ is the longitudinal CTE of fiber; $\alpha_{m}$ is the CTE of resin; $E_{f L}$ is the longitudinal modulus of fiber; and $E_{m}$ is the modulus of resin.

The transverse CTE of the lamina is calculated by Hashin's concentric cylinder model [30].

$$
\begin{aligned}
\alpha_{22} & =\hat{\alpha}_{22}+\left(\bar{S}_{12}-\hat{S}_{12}\right)\left[\left(\alpha_{f L}-\alpha_{m}\right) P_{11}+2\left(\alpha_{f T}-\alpha_{m}\right) P_{12}\right] \\
& +\left(\bar{S}_{22}-\hat{S}_{22}\right)\left[\left(\alpha_{f L}-\alpha_{m}\right) P_{12}+\left(\alpha_{f T}-\alpha_{m}\right)\left(P_{22}+P_{23}\right)\right] \\
& +\left(\bar{S}_{23}-\hat{S}_{23}\right)\left[\left(\alpha_{f L}-\alpha_{m}\right) P_{12}+\left(\alpha_{f T}-\alpha_{m}\right)\left(P_{22}+P_{23}\right)\right]
\end{aligned}
$$

where $\bar{S}_{i j}$ and $\hat{S}_{i j}$ are the effective and average composite compliance, respectively; $\alpha_{f T}$ is the transverse CTE of fiber; and $P_{i j}$ is given by 


$$
\begin{aligned}
& P_{11}=\left(A_{22}^{2}-A_{23}^{2}\right) / \operatorname{det} \mathbf{A} \\
& P_{12}=\left(A_{12} A_{23}-A_{22} A_{12}\right) / \operatorname{det} \mathbf{A} \\
& P_{22}=\left(A_{11} A_{22}-A_{12}^{2}\right) / \operatorname{det} \mathbf{A} \\
& P_{23}=\left(A_{12}^{2}-A_{11} A_{23}\right) / \operatorname{det} \mathbf{A}
\end{aligned}
$$

where $\mathbf{A}=\mathbf{S}^{(\mathbf{f})}-\mathbf{S}^{(\mathbf{m})} ; \operatorname{det} \mathbf{A}=A_{11}\left(A_{22}^{2}-A_{23}^{2}\right)+2 A_{12}\left(A_{12} A_{23}-A_{22} A_{12}\right)$; and $\mathbf{S}^{(\mathbf{f})}$ and $\mathbf{S}^{(\mathbf{m})}$ are the compliance matrix of fiber and resin, respectively.

\subsection{Finite element analysis}

A composite T-stiffener part usually consists of a number of repeating stiffener sub-units, as shown in Figure 2. Each sub-unit consists of the skin and two L-frames. In this study, a fourstiffener structure is studied as an example. The relevant dimensions are: $L=400 \mathrm{~mm} ; L_{b}=$ $200 \mathrm{~mm} ; H=150 \mathrm{~mm}$; and $h=2 \mathrm{~mm}$.

As shown in Figure 3, the skin consists of 16 laminas and the stacking sequence is [45/0/45/90/45/0/-45/0 $]_{s}$; the left and right ribs consist of 8 laminas and the stacking sequences are [-45/0/45/90/-45/0/45/0] and [45/0/-45/90/45/0/-45/0], respectively. The fiber volume fraction is $50 \%$. The noodle area is usually filled with unidirectional fibers and it is assumed that the noodle fiber volume fraction is $30 \%$. It can be seen that the stacking sequences of the two L-frames being bonded to the skin are asymmetric and thus some warpage is expected. 

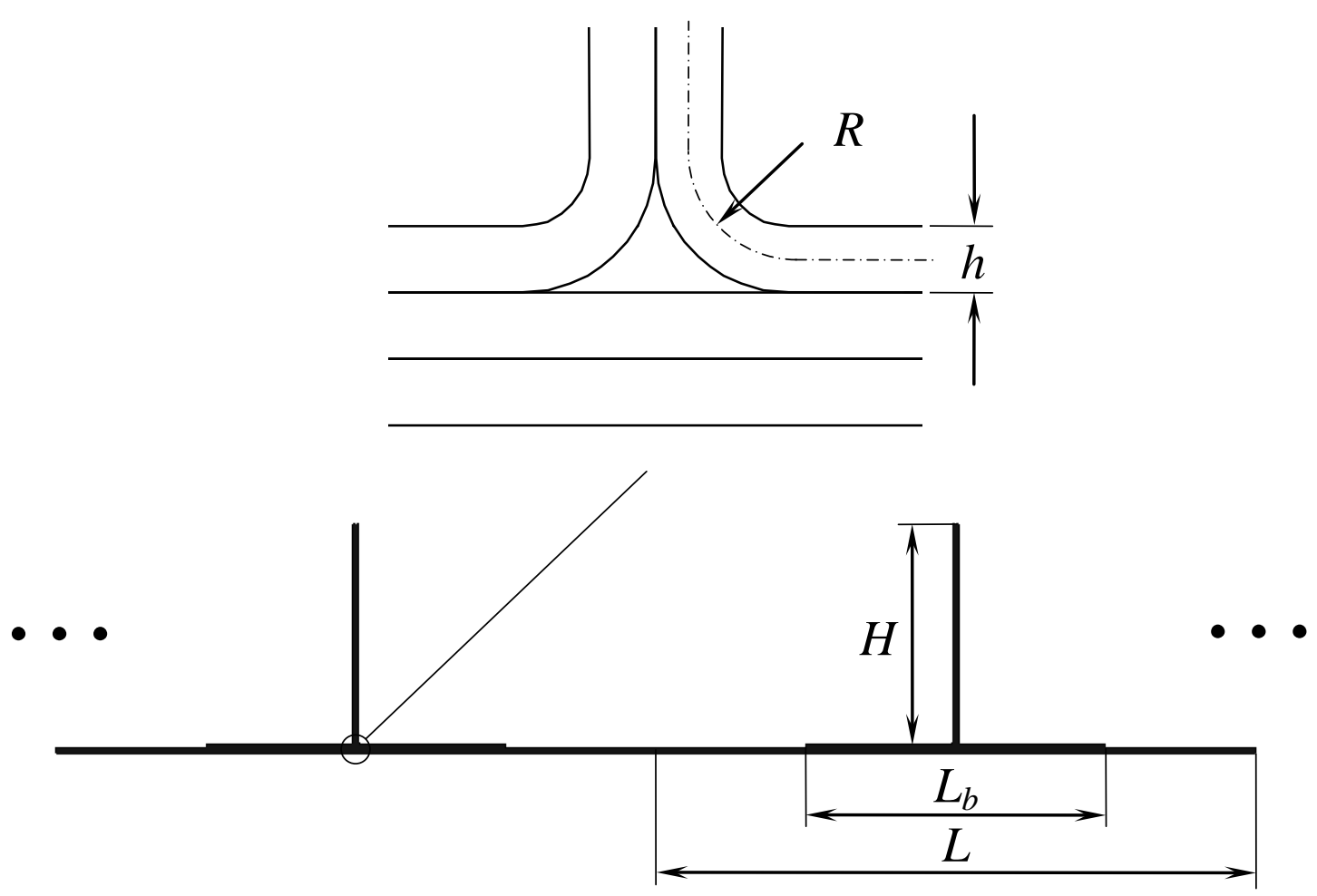

Figure 2: A composite part consisting of repeating stiffener subunits

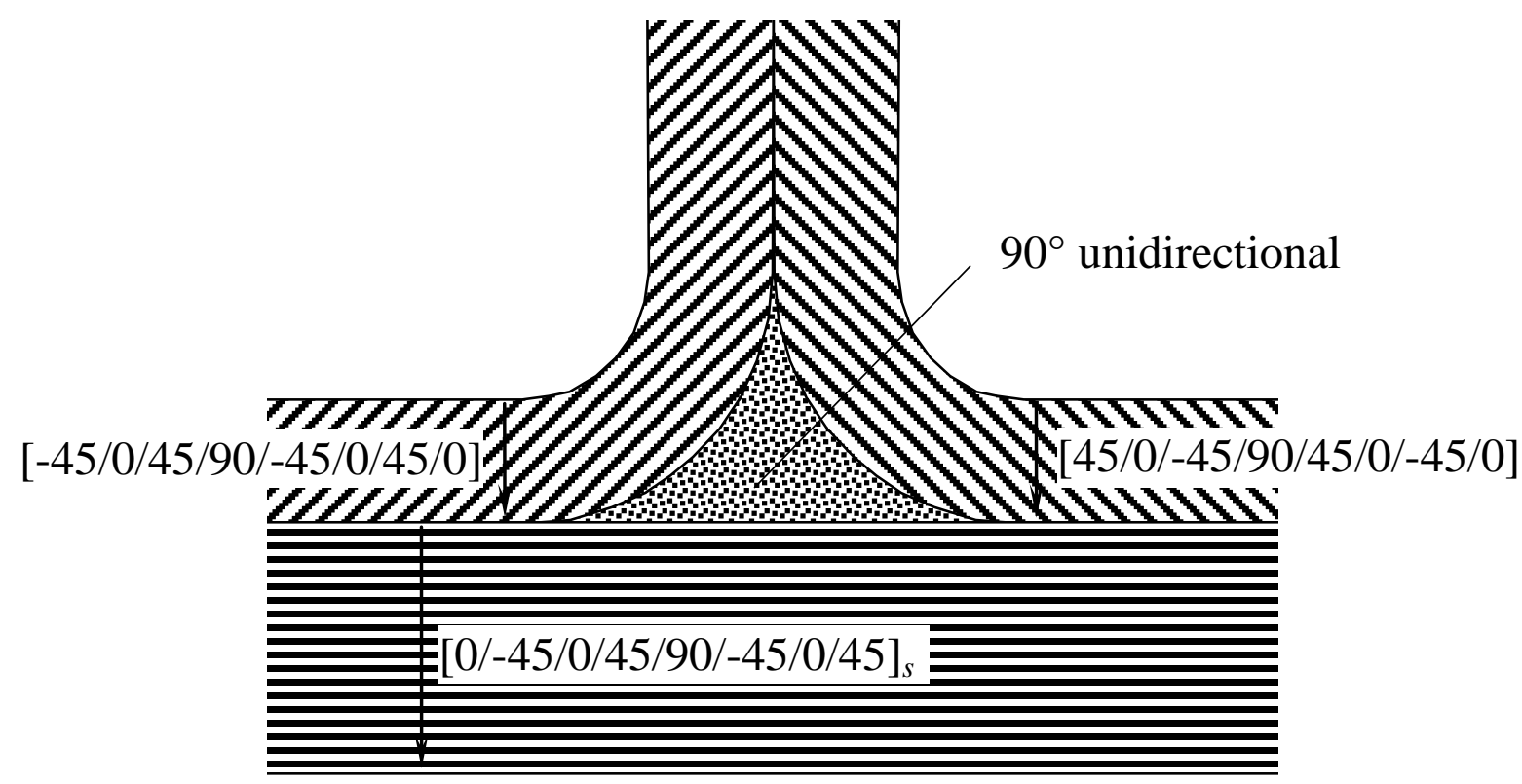

Figure 3: Stacking sequences

A commercial FEA package MSC.Marc Mentat was employed in this study. Eight-noded, isoparametric, three-dimensional brick elements are used. Because of the symmetry, only 
half of the structure is modeled and the part is restrained at the left-hand edge. In order to simulate the cooling process, the initial and final temperatures are defined to be $150^{\circ} \mathrm{C}$ and the room temperature. After computation, the resulting deformation is shown in Figure 4. The contour shows the total displacement in mm. The deformation is like "spring-in", i.e. reduction in the angle between the skin and the stiffeners. This is caused by the in-plane and through-thickness CTE mismatch of the L-frames, and constraints due to the skin and the noodle areas. Although it is also shown that some warpage exists due to the asymmetric stacking sequences at the L-frames being bonded to the skin, this warpage is insignificant when being compared to the spring-in.

\section{$\delta_{y}(\mathrm{~mm})$}
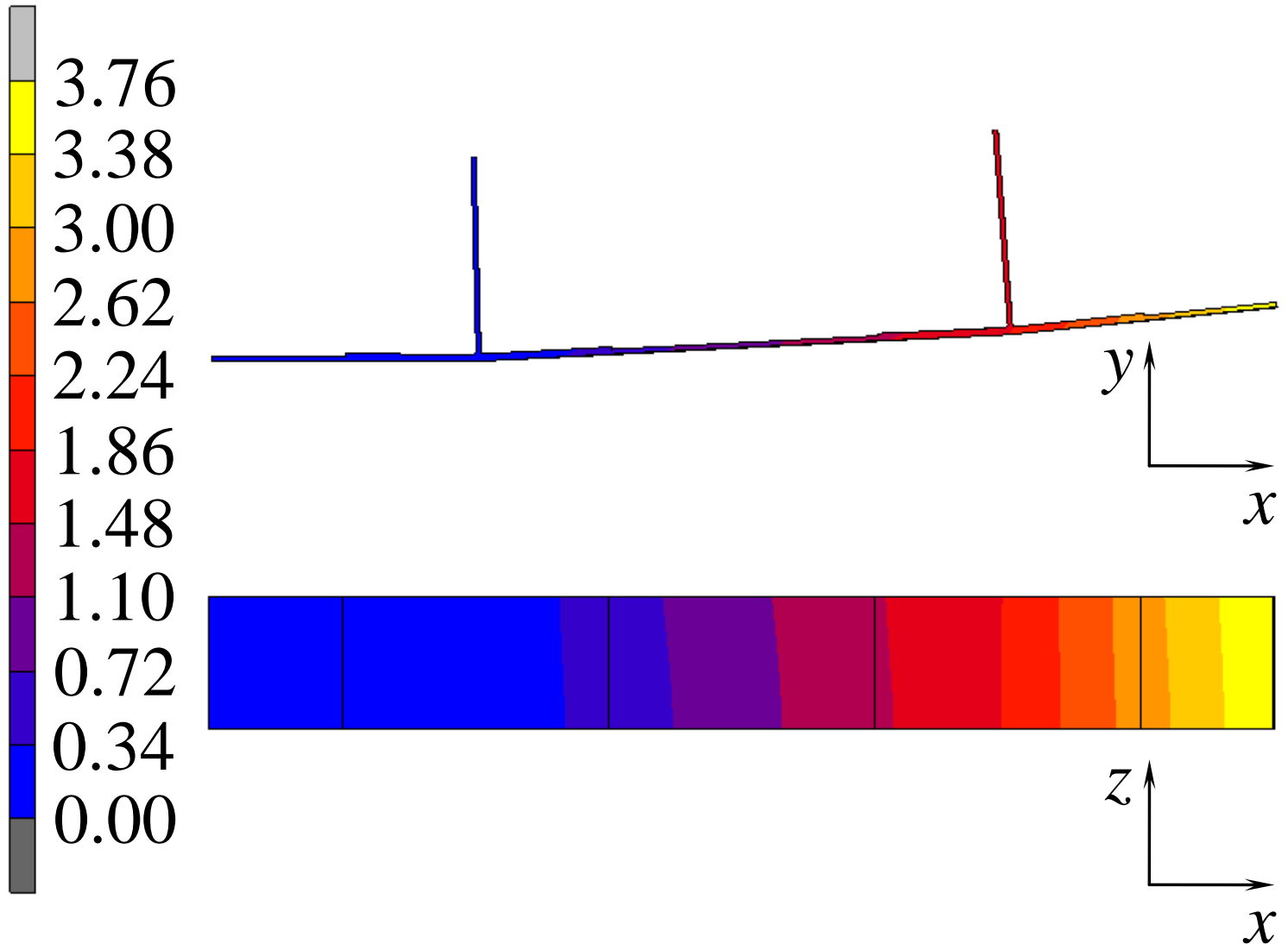

Figure 4: Deformation of the stiffener structure (mm) 


\subsection{Deformation characterization}

For this four-stiffener composite structure, it is shown that the displacement $\underline{\delta}_{y_{-}}$of the skin $\delta_{y^{\prime}}$ linearly increases with $x$; and the displacement $\underline{\delta}_{\underline{x}}$ of the stiffeners $\delta_{x^{*}}$-linearly decreases with $y$ as shown in Figure 5. Because of these linear relationships, for a T-stiffener structure, the deformation can be characterized by the spring-in of the skin $\theta_{s}$. It is reasonable to conclude that $\theta_{s}$ is independent of $L$ and $H$. The other angular displacements $\theta_{r 1}, \theta_{r 2}$, and $\theta_{s 2}$ as shown in Figure 5 are derived as

$$
\begin{aligned}
& \theta_{r 1}=\theta_{s} / 2 \\
& \theta_{r 2}=\theta_{s}+\theta_{r 1}=3 \theta_{s} / 2 \\
& \theta_{s 2}=2 \theta_{s}
\end{aligned}
$$

These relationships also suggest that these two stiffeners have little interaction with each other. For this AS4 graphite/epoxy composite T-stiffener structure, it is shown from the calculation that $\theta_{s}=0.2763^{\circ}$.

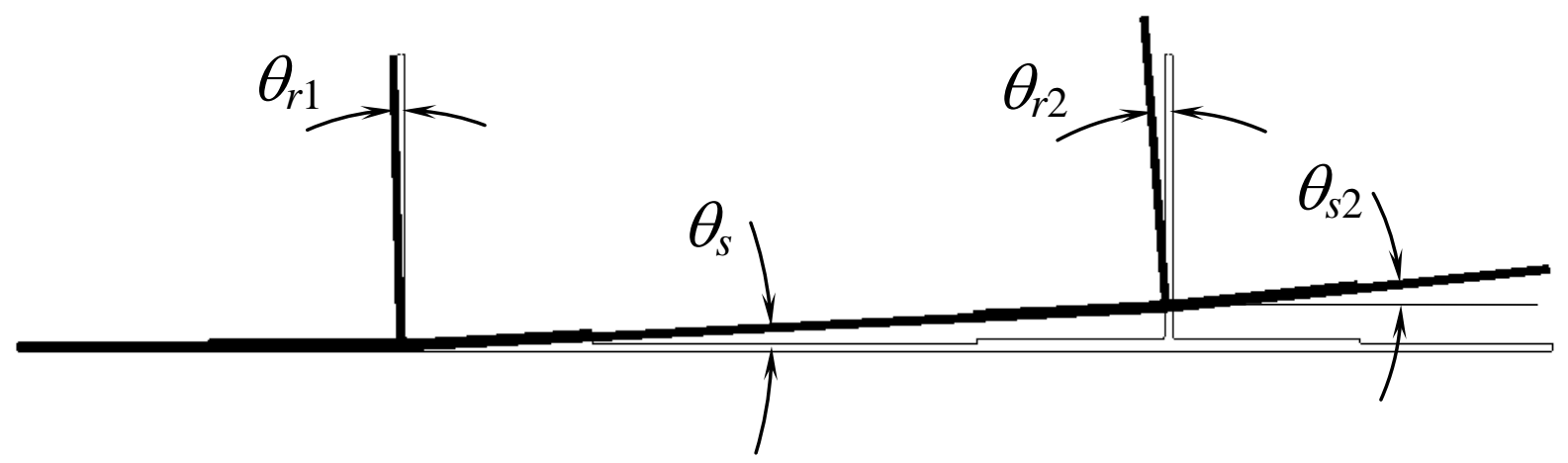

Figure 5: Angular displacements 


\section{Parametric Study}

\subsection{Selection of design parameters}

The influence of the design parameters on $\theta_{s}$ is investigated. For a given material system, the potential variables affecting the process-induced deformation include $L, L_{b}, H, R, h, V_{f}$, and $V_{f n}$. It is shown from the aforementioned analysis that $\theta_{s}$ is independent of $L$ and $H$. To account for the influence of bond length $L_{b}$, a dimensionless variable $L_{b} / L$ is introduced. It is also shown from FEA that the spring-in is constant when the model is scaled up or down, i.e. the radius/thickness ratio is constant. Thus, it is concluded that $\theta_{s}$ is dependent on $R / h$. With the introduction of dimensionless variables, the design factors to be investigated are reduced to $L_{b} / L, R / h$, and $V_{f}$ and $V_{f n}$.

\subsection{Bond length}

First, the effect of the bond length $L_{b}$ is investigated. Two fiber volume fraction combinations $V_{f}=50 \% ; V_{f n}=30 \%$ and $V_{f}=60 \% ; V_{f n}=50 \%$ are studied. For each fiber volume fraction combination, $L_{b} / L$ is varied from 0.125 to 1 and $\theta_{s}$ was calculated by FEA when $R / h=1.5,3$, and 5 , respectively. The dimensionless $\theta_{s}$ is derived as

$$
\underline{\theta}_{s}=\frac{\theta_{s}}{\left.\theta_{s}\right|_{L_{b} / L=0.5}}
$$

$\underline{\theta}_{s}$ vs. $L_{b} / L$ is shown in Figure 6. The data is fit to a power model as

$$
\underline{\theta}_{s}=0.93+0.22\left(L_{b} / L\right)^{1.52}
$$




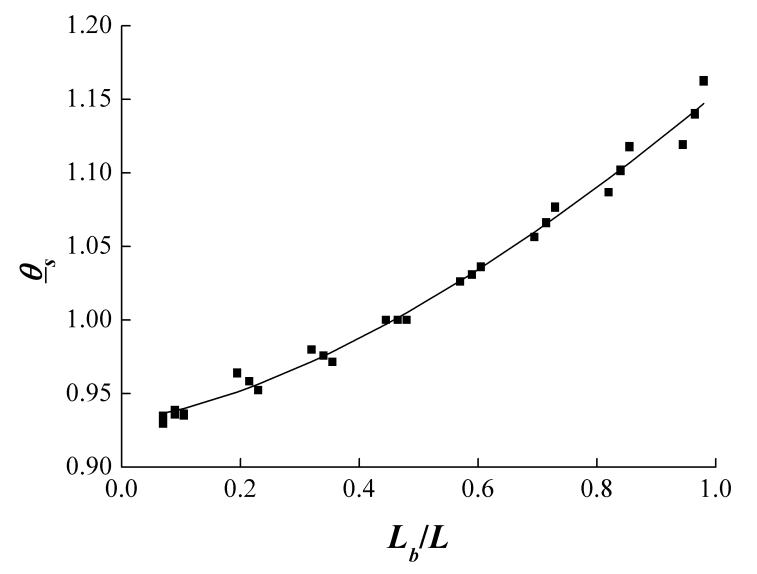

Figure 6: $\underline{\theta}_{s}$ vs. $\boldsymbol{L}_{b} / \mathbf{L}$

In the following modeling and analysis, $L_{b}$ is fixed at $0.5 L$ and $\left.\theta_{s}\right|_{L_{b} / L=0.5}$ is denoted as $\theta_{s}$ for simplicity.

\subsection{Radius and thickness}

Second, the influence of $R / h$ is investigated. In this study, the thickness $h$ is fixed at $2 \mathrm{~mm}$ and three different radii $3 \mathrm{~mm}, 6 \mathrm{~mm}$, and $10 \mathrm{~mm}$ are chosen. Thus, the corresponding $R / h$ is 1.5 , 3, and 5, respectively. $V_{f}$ and $V_{f n}$ are varied from $30 \%$ to $60 \%$ and $30 \%$ to $50 \%$, respectively. For each fiber volume fraction combination, $\theta_{s}$ was calculated by FEA. Partial results are shown in Figure 7. 


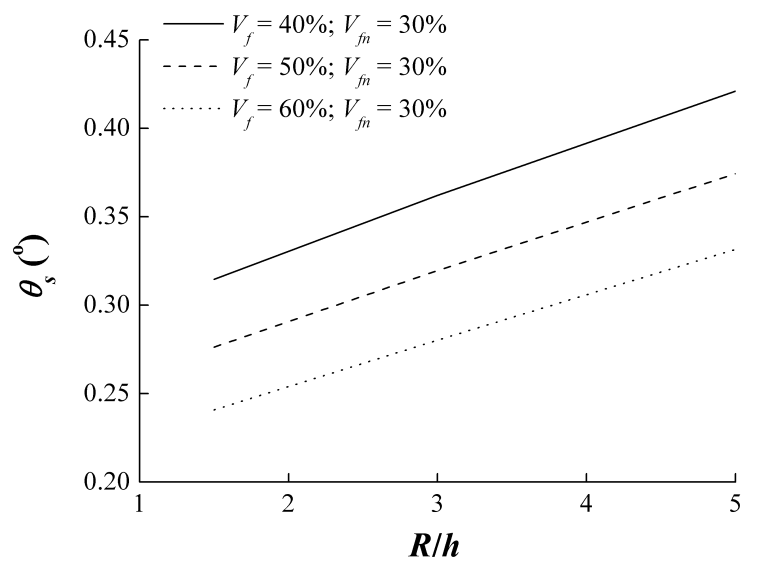

Figure 7: $\theta_{s}$ vs. $R / h$

It is implied from Figure 7 that $\theta_{s}$ linearly increases with $R / h$. Thus, $\theta_{s}$ is given by

$$
\theta_{s}=\theta_{s 0}[1+k(R / h)]
$$

where $\theta_{s 0}$ is the angular displacement when $R$ approaches zero; and $k$ represents the slope. For each fiber volume fraction combination, $\theta_{\mathrm{s} 0}$ and $k$ are derived, and these are analyzed in the next subsection.

\subsection{Fiber volume fraction}

Since $\theta_{s 0}$ and $k$ are dependent on both $V_{f}$ and $V_{f n}$, they are plotted as contours shown in Figure 8, from which it is shown that both $\theta_{s 0}$ and $k$ are linearly dependent on $V_{f}$ and $V_{f n}$. Thus, the following linear regression models can be obtained.

$$
\begin{aligned}
& \theta_{s 0}=0.41-0.336 V_{f}-0.0224 V_{f n} \\
& k=0.0986+0.0768\left(V_{f}-0.73 V_{f n}\right)
\end{aligned}
$$



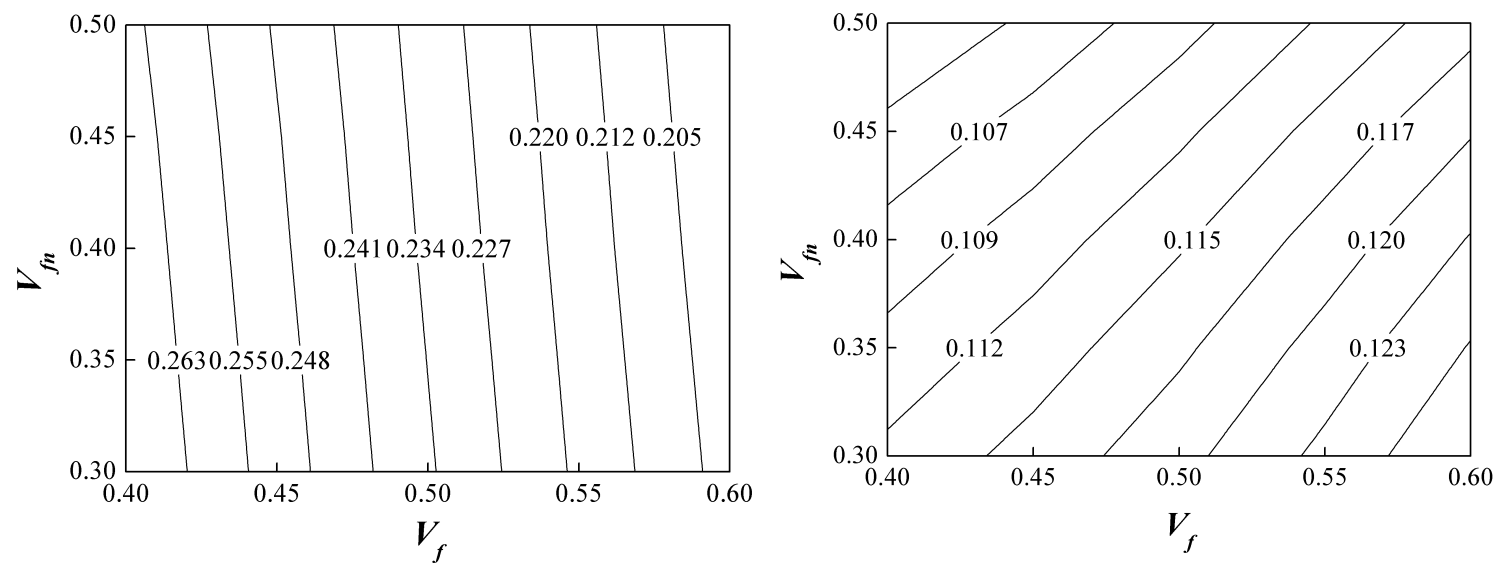

Figure 8: Left: $\theta_{s 0}$ vs. $V_{f}$ and $V_{f n}$; right: $k$ vs. $V_{f}$ and $V_{f n}$

Eqn. 13 is only valid for the AS4 graphite/epoxy composites being currently studied. For other composite materials, a general equation is derived as

$$
\theta_{s 0}=a_{0}+a_{1} V_{f}+a_{2} V_{f n}
$$

where $a_{0}, a_{1}$, and $a_{2}$ are constants and dependent on the material system.

\subsection{Summary}

In summary, the regression model for $\theta_{s}$ of the AS4 graphite/epoxy composite T-stiffener structures is given by

$$
\begin{aligned}
\theta_{s}= & \left(0.41-0.336 V_{f}-0.0224 V_{f n}\right)\left(1+\left[0.0986+0.0768\left(V_{f}-0.73 V_{f n}\right)(R / h)\right\}\right. \\
& {\left[0.93+0.22\left(L_{b} / L\right)^{1.52}\right] }
\end{aligned}
$$

\section{Sensitivity Analysis}

When there is variation in any design parameter, e.g. $V_{f}$, the resulting $\theta_{s}$ will vary accordingly. Thus, the sensitivities of $\theta_{s}$ to these design parameters need to be studied. When there is a small deviation in $V_{f}$, i.e. $\Delta V_{f}$, the deviation of $\theta_{s}$ is given by 


$$
\Delta \theta_{s}=\frac{\partial \theta_{s}}{\partial V_{f}} \Delta V_{f}
$$

If relative quantities are used, Eqn. 17 is rewritten as

$$
\frac{\Delta \theta_{s}}{\theta_{s}}=\frac{V_{f} \partial \theta_{s}}{\theta_{s} \partial V_{f}} \cdot \frac{\Delta V_{f}}{V_{f}}
$$

Thus, the sensitivity of $\theta_{s}$ to $V_{f}$ is given by

$$
S\left(V_{f}\right)=\frac{V_{f} \partial \theta_{s}}{\theta_{s} \partial V_{f}}
$$

Similarly, the sensitivities of of $\theta_{s}$ to the other design variables are given by

$$
\begin{aligned}
& S\left(V_{f n}\right)=\frac{V_{f n} \partial \theta_{s}}{\theta_{s} \partial V_{f n}} \\
& S(R / h)=\frac{(R / h) \partial \theta_{s}}{\theta_{s} \partial(R / h)} \\
& S\left(L_{b} / L\right)=\frac{\left(L_{b} / L\right) \partial \theta_{s}}{\theta_{s} \partial\left(L_{b} / L\right)}
\end{aligned}
$$

The partial derivatives are derived from Eqn. 16 as

$$
\begin{gathered}
\frac{\partial \theta_{s}}{\partial V_{f}}=\left[-0.336+\left(-1.64 \times 10^{-3}-0.0516 V_{f}+0.0171 V_{f n}\right)(R / h)\right] \\
{\left[0.93+0.22\left(L_{b} / L\right)^{1.52}\right]} \\
\frac{\partial \theta_{s}}{\partial V_{f n}}=\left[-0.0224+\left(-0.0252+0.0171 V_{f}+2.51 \times 10^{-3} V_{f n}\right)(R / h)\right] \\
{\left[0.93+0.22\left(L_{b} / L\right)^{1.52}\right]} \\
\frac{\partial \theta_{s}}{\partial(R / h)}=\left(0.41-0.336 V_{f}-0.0224 V_{f n}\right)\left[0.0986+0.0768\left(V_{f}-0.73 V_{f n}\right)\right] \\
{\left[0.93+0.22\left(L_{b} / L\right)^{1.52}\right]}
\end{gathered}
$$




$$
\begin{aligned}
\frac{\partial \theta_{s}}{\partial\left(L_{b} / L\right)}= & 0.334\left(0.41-0.336 V_{f}-0.0224 V_{f n}\right) \\
& \left\{1+\left[0.0986+0.0768\left(V_{f}-0.73 V_{f n}\right)\right](R / h)\right\}\left(L_{b} / L\right)^{0.52}
\end{aligned}
$$

When $V_{f}=40 \% ; V_{f n}=30 \%$ and $V_{f}=60 \% ; V_{f n}=30 \%$, the sensitivities to the design parameters are shown in Figure 9.

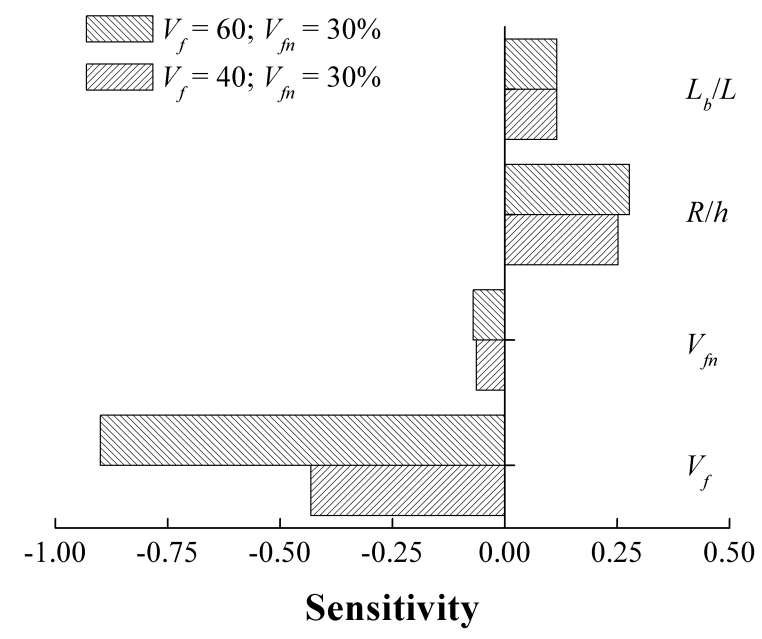

Figure 9: Sensitivity of $\theta_{s}$ to the design parameters

It can be seen from Figure 9 that $\theta_{s}$ is most sensitive to the laminate fiber volume fraction, followed by $R / h$ and the bond length, and least sensitive to the noodle fiber volume fraction. It is also seen that $\theta_{s}$ is more sensitive to $V_{f}$ at higher $V_{f}$.

\section{Conclusions}

A parametric study on the process-induced deformation of composite T-stiffener structures is presented in this paper. The deformation was calculated numerically by FEA. The results suggest that the overall deformation of the structure can be characterized by the spring-in of the skin. Based on FEA, a parametric study and sensitivity analysis was conducted, from 
which it is shown that: (1) the spring-in decreases with the fiber volume fraction; (2) the spring-in linearly increases with the radius-thickness ratio; (3) the spring-in vs. the bonding length is a power increasing function; (4) the spring-in is most sensitive to the laminate fiber volume fraction, followed by the radius-thickness ratio and the bond length, and least sensitive to the noodle fiber volume fraction; and (5) at higher fiber volume fractions, the spring-in is more sensitive to the fiber volume fraction. The spring-in angle of composite TStiffener structures is mainly studied in this paper. However, because the laminate where the stiffener is bonded to the skin is not symmetric and balanced, the torsion deformation should be considered in the future study.

\section{Acknowledgement}

The author acknowledges the support from the Curtin Research Fellowship.

\section{References}

1. (2002) Military Handbook - MIL-HDBK-17-3F: Composite Materials Handbook, Volume 3 - Polymer Matrix Composites Materials Usage, Design, and Analysis, U.S. Department of Defense.

2. Cairns, D. S., Samborsky, D. D., Haugen, D. J. and Mandell, J. F. (1998) Fracture of skin/stiffener intersections in composite wind turbine structures. 1998 ASME Wind Energy Symposium and 36th AIAA Aerospace Sciences Meeting and Exhibit. Reno, NV, ASME International.

3. Hahn, H. T. and Pagano, N. J. (1975) Curing stress in composite laminates. Journal of Composite Materials, 9: p. 91-105.

4. Radford, D. W. and Diefendorf, R. J. (1993) Shape instabilities in composite resulting from laminate anisotropy. Journal of Reinforced Plastics and Composites, 12(1): p. 58-75.

5. Huang, C. K. and Yang, S. Y. (1997) Warping in advanced composite tools with varying angles and radii. Composites Part A, 28(9-10): p. 891-893.

6. Kollar, L. P. (1994) Approximate analysis of the temperature induced stresses and deformations of composite shells. Journal of Composite Materials, 28(5): p. 392-414.

7. Jain, L. K., Lutton, B. G., Mai, Y. W. and Paton, R. (1997) Stresses and deformations induced during manufacturing. Part II: a study of the spring-in phenomenon. Journal of Composite Materials, 31(7): p. 696-719.

8. Jain, L. K. and Mai, Y. W. (1997) Stresses and deformations induced during 
manufacturing. Part I: theoretical analysis of composite cylinders and shells. Journal of Composite Materials, 31(7): p. 673-695.

9. Darrow, J., D. A. and Smith, L. V. (2002) Isolating components of processing induced warpage in laminated composites. Journal of Composite Materials, 36(21): p. 24072419.

10. Radford, D. W. and Rennich, T. S. (2000) Separating sources of manufacturing distortion in laminated composites. Journal of Reinforced Plastics and Composites, 19(8): p. 621-641.

11. Wisnom, M. R., Potter, K. D. and Ersoy, N. (2007) Shear-lag analysis of the effect of thickness on spring-in of curved composites. Journal of Composite Materials, 41(11): p. 1311-1324.

12. Wang, J., Kelly, D. and Hillier, W. (2000) Finite element analysis of temperature induced stresses and deformations of polymer composite components. Journal of Composite Materials, 34(17): p. 1456-1471.

13. Ding, Y., Chiu, W. K. and Liu, X. L. (2001) Anisotropy related 'spring-in' of angled composite shells. Polymers \& Polymer Composites, 9(6): p. 393-401.

14. Clifford, S., Jansson, N., Yu, W., Michaud, V. and Manson, J.-A. (2006) Thermoviscoelastic anisotropic analysis of process induced residual stresses and dimensional stability in real polymer matrix composite components. Composites Part A, 37(4): p. 538-545.

15. Weitsman, Y. (1979) Residual thermal stresses due to cool-down of epoxy-resin composites. Journal of Applied Mechanics, 46(3): p. 563-567.

16. Wang, T. M., Daniel, I. M. and Gotro, J. T. (1992) Thermoviscoelastic analysis of residual stresses and warpage in composite laminates. Journal of Composite Materials, 26(6): p. 883-899.

17. White, S. R. and Hahn, H. T. (1992) Process modeling of composite materials: residual stress development during cure. Part I: model formulation. Journal of Composite Materials, 26(16): p. 2402-2422.

18. White, S. R. and Hahn, H. T. (1992) Process modeling of composite materials: residual stress development during cure. Part II: experimental validation. Journal of Composite Materials, 26(16): p. 2423-2454.

19. Li, M. C., Wu, J. J., Loos, A. C. and Morton, J. (1997) A plane-strain finite element model for process-induced residual stresses in a graphite/PEEK composite. Journal of Composite Materials, 31(3): p. 212-243.

20. Wiersma, H. W., Peeters, L. J. B. and Akkerman, R. (1998) Prediction of springforward in continuous-fiber/polymer L-shaped parts. Composites Part A, 29(11): p. 1333-1342.

21. Fernlund, G., Osooly, A., Poursartip, A., Vaziri, R., Courdji, R., Nelson, K., George, P., Hendrickson, L. and Griffith, J. (2003) Finite element based prediction of processinduced deformation of autoclaved composite structures using 2D process analysis and 3D structural analysis. Composite Structures, 62(2): p. 223-234.

22. Johnston, A., Vaziri, R. and Poursartip, A. (2001) A plane strain model for processinduced deformation of laminated composite structures. Journal of Composite Materials, 35(16): p. 1435-1469.

23. Zhu, Q., Geubelle, P. H., Li, M. and Tucker, C. L., III (2001) Dimensional accuracy of thermoset composites: simulation of process-induced residual stresses. Journal of Composite Materials, 35(2): p. 2171-2205.

24. Li, J., Yao, X., Liu, Y., Cen, Z., Kou, Z. and Dai, D. (2009) A study of the integrated composite material structures under different fabrication processing. Composites Part A, 40(4): p. 455-462. 
25. Adolf, D. and Chambers, R. (1997) Verification of the capability for quantitative stress prediction during cure. Polymer, 38(21): p. 5481-5490.

26. Garstka, T., Ersoy, N., Potter, K. and Wisnom, M. R. (2007) In-situ measurement of through-the-thickness strains during processing of AS4/8552 composite. Composites Part A, 38(12): p. 2517-2526.

27. Li, C., Potter, K., Wisnom, M. R. and Stringer, G. (2004) In-situ measurement of chemical shrinkage of MY750 epoxy resin by a novel gravimetric method. Composite Science and Technology, 64(1): p. 55-64.

28. Adams, D. F. (1989) Properties characterization - mechanical/physical/hygrothermal properties test methods. IN LEE, S. M. (Ed.) Reference Book for Composites Technology Lancaster, PA, Technomic Pub Co.

29. Chou, T.-W. (1992) Microstructural Design of Fiber Composites, Cambridge, U.K., Cambridge University Press.

30. Bowles, D. E. and Tompkins, S. S. (1989) Prediction of coefficients of thermal expansion for unidirectional composites. Journal of Composite Materials, 23(4): p. 370-388. 